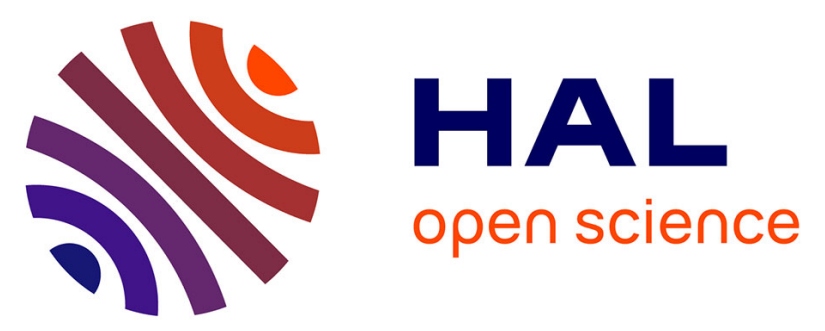

\title{
The combined effects of activity space and neighbourhood of residence on participation in preventive health-care activities: The case of cervical screening in the Paris metropolitan area (France).
}

Julie Vallée, Emmanuelle Cadot, Francesca Grillo, Isabelle Parizot, Pierre Chauvin

\section{To cite this version:}

Julie Vallée, Emmanuelle Cadot, Francesca Grillo, Isabelle Parizot, Pierre Chauvin. The combined effects of activity space and neighbourhood of residence on participation in preventive health-care activities: The case of cervical screening in the Paris metropolitan area (France).. Health \& Place, 2010, 16 (5), pp.838-52. 10.1016/j.healthplace.2010.04.009 . inserm-00510306

\section{HAL Id: inserm-00510306 https://www.hal.inserm.fr/inserm-00510306}

Submitted on 18 Aug 2010

HAL is a multi-disciplinary open access archive for the deposit and dissemination of scientific research documents, whether they are published or not. The documents may come from teaching and research institutions in France or abroad, or from public or private research centers.
L'archive ouverte pluridisciplinaire HAL, est destinée au dépôt et à la diffusion de documents scientifiques de niveau recherche, publiés ou non, émanant des établissements d'enseignement et de recherche français ou étrangers, des laboratoires publics ou privés. 


\title{
The combined effects of activity space and neighbourhood of residence on participation in preventive health-care activities. The case of cervical screening in the Paris metropolitan area (France)
}

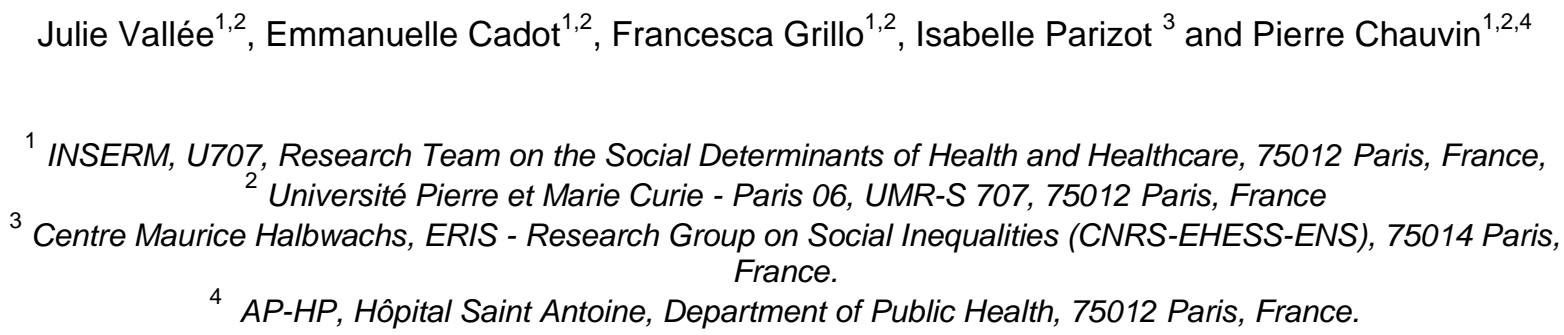

\begin{abstract}
Estimates from multilevel regression of 1768 women living in the Paris metropolitan area showed that women who reported concentrating their daily activities in their perceived neighbourhood of residence had a statistically greater likelihood of not having undergone cervical screening during the previous two years. Furthermore, the characteristics of the administrative neighbourhood of residence (such as the practitioner density or the proportion of residents with a recent preventive consultation) had a statistically greater impact in terms of delayed cervical screening on women who concentrated the vast majority of their daily activities within their perceived neighbourhood of residence than among those who did not. The residential environment might promote or damage, to a greater extent, the health behaviour of people whose daily activities are concentrated within their perceived neighbourhood, since we can assume that their exposure to their neighbourhood characteristics is stronger.

It could thus be useful to study more often the combined effects of activity space and neighbourhood of residence on participation in preventive health-care activities.
\end{abstract}

\section{Keywords}

activity space; daily mobility; neighbourhood of residence; cross-level interaction; preventive health care. 


\section{Background}

Daily mobility, determined by observing people's routine "activity space", is arousing a great deal of interest in the social sciences in the tradition of time geography, as originally developed by Hägerstrand (1967; 1970). Activity space may be defined as the space within which people move about or travel in the course of their daily activities. Various measures of activity space have been used in time geography to identify social differences in people's access to opportunities (Golledge and Stimson, 1997), in particular, access to health-care facilities (Arcury et al., 2005; Nemet and Bailey, 2000; Sherman et al., 2005). In addition to the conventional notion of distance (e.g., the spatial separation between a patient's residence and his/her care provider's office), activity space is considered in these studies an "enabling" factor for health services utilization, as per Andersen's health behaviour model (Andersen, 1995).

Historically, activity space has been operationalized using the standard deviational ellipse of the locations of regular activities (Lefever, 1926; Yuill, 1971). This ellipse was used to compare daily activity space and health-care seeking spaces (Cromley and Shannon, 1986; Gesler and Meade, 1988; Shannon et al., 1978). More recently, geographers implemented daily travel datasets in geographical information systems (GIS) to represent an individual's activity space in three dimensions (with two axes specifying the location on the Earth's surface and the third, a time axis) as a space-time aquarium (Kwan, 1999; Kwan and Lee, 2003). This geovisualization of human activity patterns has been used to study exposure to infectious disease transmission (Löytönen, 1998; Schaerstrom, 1996; Watts et al., 1998) and could be advantageously used in connection with health-care utilization. However, this approach involves the use of travel datasets, which are difficult to collect and analyse, particularly in a survey with a large population sample.

We propose here to use a simplified measure of activity space based on the respondents' statements: they were asked whether some of their social and domestic activities took place within their neighbourhood of residence. This measure of activity space actually corresponds to a spatial overlap between what respondents consider the space of their neighbourhood of residence and what they consider the spatial extent of their daily activities. This measure of activity space was, therefore, not defined on the basis of the precise location of the daily activities, but was instead directly linked to the respondents' neighbourhood representation, since they were asked to place their activities within or outside what they considered their neighbourhood of residence. In this paper, we therefore propose to define activity space as a measure of the concentration of daily activities in the perceived neighbourhood.

The first objective of this paper was to identify individual and contextual characteristics statistically associated with this measure of activity space in the Paris metropolitan area and 
to discuss the validity of this simplified measure, which may reflect the spatial extent of daily mobility but which is also closely linked to perceived neighbourhood boundaries.

The second objective of this study was to determine if this measure of activity space was associated with participation in preventive health-care activities (in this case, cervical screening in the Paris metropolitan area). We postulated that women reporting an activity space centred within their perceived neighbourhood had a greater likelihood of not having a cervical screening test performed regularly, since it can be assumed that access to healthcare facilities and to a number of social interaction opportunities, which contribute to changing health-care norms, can vary according to the activity space.

Lastly, the third objective of this article was to study the combined effects of neighbourhood characteristics and activity space on participation in cervical screening. We postulated that the effects of neighbourhood characteristics on health behaviour might be modified by the respondent's activity space. Neighbourhoods of residence have recently emerged in social epidemiology, health geography and public health literature as a relevant contextual characteristic to be fruitfully taken into account. Many studies based on multilevel regression models have shown that neighbourhoods possess both physical and social attributes that can promote or damage people's health (Diez- Roux, 2001; Macintyre and Ellaway, 2000; Macintyre and Ellaway, 2003). With regard to health care utilization and, more specifically, the use of preventive care services, the multilevel approach has revealed, among other things, the effect of area-level poverty rate on participation in cancer screening, after adjustment for individual factors (Schootman et al., 2006). Moreover, studies using multilevel methods have underscored the importance of not assuming that the health effects of the residential context operate identically for different types of people (Stafford et al., 2005). As pointed out by Macintyre and Ellaway, there is no a priori reason to assume that neighbourhood influences on health are similar for all populations (Macintyre and Ellaway, 2003). Indeed, it has been shown that the effects of the residential environment on health outcomes vary according to the resident's sex (Macintyre, 2001; Raleigh and Kiri, 1997; Stafford et al., 2005), age (Chaix et al., 2007; Chaix et al., 2005b; Waitzman and Smith, 1998), race and ethnicity (Benjamins et al., 2004; Coughlin et al., 2008) and socioeconomic status (Cummins et al., 2005; Ecob and Macintyre, 2000; Stafford et al., 2001; van Lenthe and Mackenbach, 2002; Yen and Kaplan, 1999). In a previous paper describing how residential contextual effects on the health status of Vientiane population (Laos) differed significantly according to the respondent's age, sex and level of deprivation, we suggested that the magnitude of neighbourhood effects may be closely associated both with neighbourhood attachment and daily mobility within Vientiane city (Vallée, 2009).

Despite the interest shown in the interactions between individual and contextual effects, to the best of our knowledge, interactions between individual activity space and residential 
neighbourhood effects have not been investigated empirically. It is even reasonable to assume that the residential environment might promote or damage, to a lesser extent, the health of people whose activity space extends beyond their residential neighbourhood, since they have less exposure to their residential neighbourhood. Considering only the effect of the neighbourhood of residence on health and excluding nonresidential exposure would lead to a "local trap", as pointed out by Cummins (2007). Inagami, Cohen and Finch (2007) showed in one of the few studies that consider the nonresidential neighbourhood environment in addition to residential neighbourhood characteristics - the need to include nonresidential neighbourhood exposure in order to accurately measure the association between the residential neighbourhood and self-rated health. Therefore, in urban areas in particular, people with a large activity space could be less influenced by their residential environment, since their daily mobility within the entire city could be seen as a way to escape from the constraints of their neighbourhood of residence. The third objective of this paper was, therefore, to determine if the effects of the administrative-neighbourhood characteristics on cervical screening participation were actually stronger among women reporting that they did the vast majority of their activities within their perceived neighbourhood.

In short, the underlying idea of this paper was to improve the characterization of "personal exposure area" (Chaix et al., 2009) by taking into account the activity space and the neighbourhood of residence.

- The activity space - defined from a concentration score for daily activities in the perceived neighbourhood - was used as a proxy of exposure to the neighbourhood of residence.

- The administrative neighbourhood - with fixed boundaries, whose scale was chosen to correspond as best possible to the collective perceived neighbourhood - was used as a proxy of the neighbourhood of residence.

The conceptual framework that guided the analysis is presented in Figure 1. The two hypotheses in this paper can be summarized as follows: the more respondents reported concentrating their daily activities within their perceived neighbourhood of residence, (1) the less they participated in preventive health-care activities and (2) the more they were influenced by the characteristics of their administrative neighbourhood. 
Figure 1. Conceptual framework for the combined impact of activity space and neighbourhood of residence on health behaviour

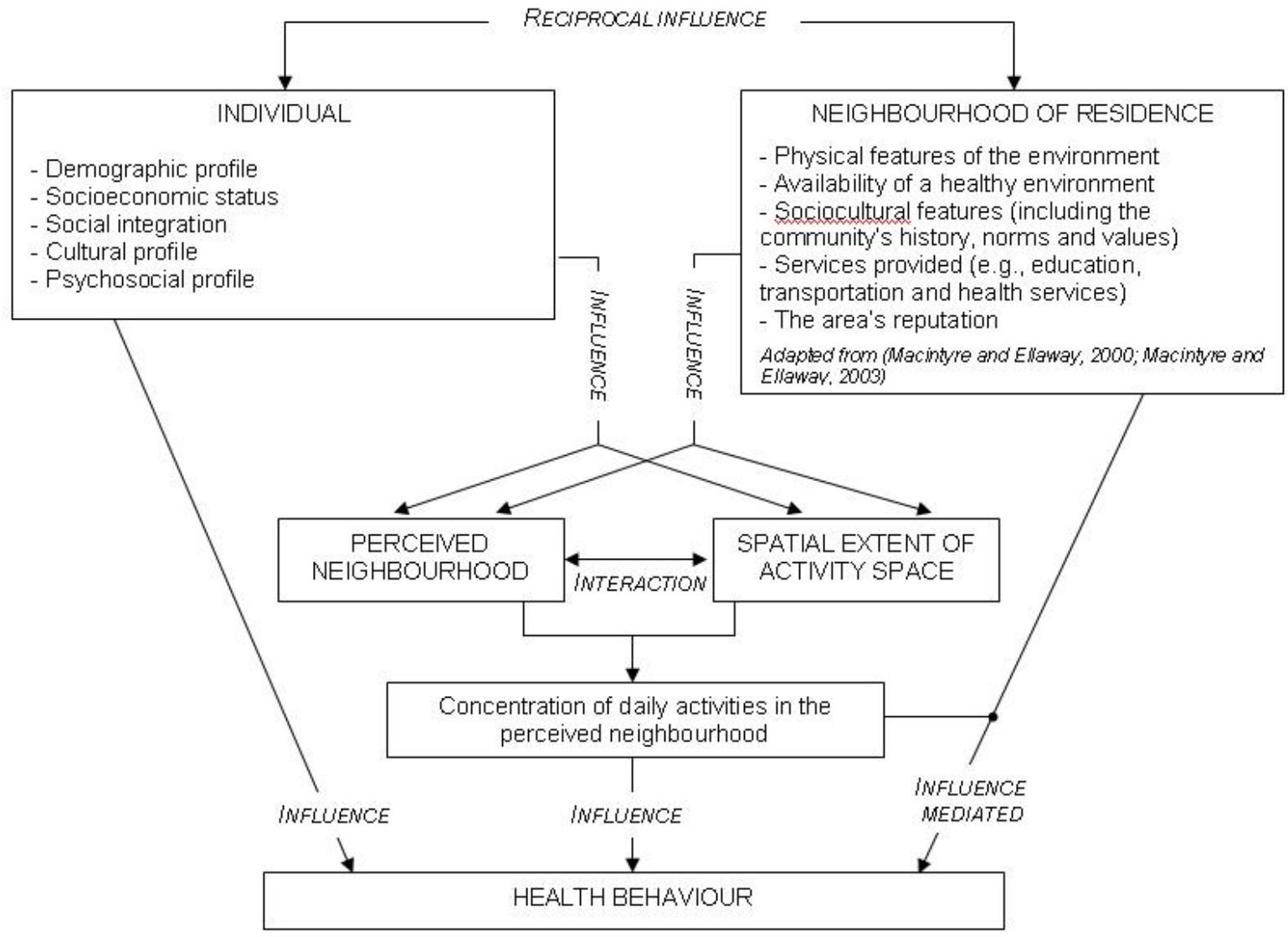

\section{Materials and methods}

\section{Study sample}

The SIRS (French acronym for Health, Inequalities and Social Ruptures) survey was conducted in the fall of 2005 among a representative sample of the adult French-speaking population in the Paris metropolitan area (Paris and its suburbs, a region with a population of 6.5 million). This survey constituted the first wave of a socioepidemiological population-based cohort study, which is a collaborative research project between the French National Institute for Health and Medical Research (INSERM) and the National Centre for Scientific Research (CNRS). Another wave was conducted during the fall and winter of 2009-2010. In this paper, data collected in 2005 were examined cross-sectionally.

The SIRS survey employed a stratified, multistage cluster sampling procedure. This sample design is commonly used in health geography because it provides appropriate datasets for studying the heterogeneity of health characteristics between different neighbourhoods and the homogeneity of characteristics within a given neighbourhood (Vallée et al., 2007). The 
primary sampling units were census blocks called "IRISs" (IRIS" is a French acronym for blocks for incorporating statistical information). They constitute the smallest census unit areas in France (with about 2,000 inhabitants each) whose aggregate data can be used on a routine basis. The Paris metropolitan area was divided into six strata according to the population's socioeconomic profile (Préteceille, 2003) in order to overrepresent the poorest neighbourhoods, and census blocks were randomly chosen within each stratum. In all, 50 census blocks were selected from the 2,595 eligible census blocks in Paris and its suburbs. Subsequently, within each selected census block, 60 households were randomly chosen from a complete list of households. Lastly, one adult was randomly selected from each household by the birthday method. A questionnaire containing numerous social and healthrelated questions was administered face-to-face during home visits. Further details on the SIRS sampling methodology were published previously (Chauvin and Parizot, 2009; Renahy et al., 2008).

\section{$\underline{\text { Variables of interest }}$}

\section{Measure of activity space}

In this paper, activity space was measured from the respondents' statements about the location of their domestic and social activities. In the SIRS survey, people were asked where they usually 1) go food shopping; 2) use services (bank, post office); 3) go for a walk; 4) meet friends; and 5) go to a restaurant or café. These five activities were selected in order to involve cognitive routines that people can easily remember (Enaux, 2009).

For each of these five activities, three answers were proposed: 1) mainly within one's residential neighbourhood; 2) mainly outside one's residential neighbourhood; 3) both within and outside one's residential neighbourhood. As stated in the introduction, the neighbourhood of residence was not defined, and its boundaries were left to the individual's own assessment and perception.

A measure of activity space was subsequently created: activities said to be done "mainly within the neighbourhood" were assigned a value of 1 , while those done "both within and outside the neighbourhood" or "mainly outside the neighbourhood" were assigned a value of 0.5 and 0 , respectively. By adding these values together and dividing the sum by the total number of reported activities, we obtained an individual score measuring the concentration of daily activities in the perceived neighbourhood. The respondents were then ranked on the basis of this score. It ranged from 0 (for people who reported doing all the activities of interest mainly outside their neighbourhood of residence) to 1 (for people who reported doing all the activities of interest mainly within their neighbourhood of residence) and can be viewed as a proxy of personal exposure to the neighbourhood of residence. 
To facilitate the cross-level interaction analysis, we also decided to isolate the respondents who reported doing the vast majority of their daily activities within their perceived neighbourhood of residence.

\section{Cervical screening}

Cervical cancer screening with a Papanicolaou (Pap) smear test is the key procedure to early detection and improved chances of survival from this type of cancer (Baker and Middleton, 2003). In France, gynaecologists perform - in independent practice - the vast majority of cervical screening, even if general practitioners can perform or order screening tests. Since 1995, in France, it is recommended that a smear test be performed every three years after two normal annual smear tests (ANDEM, 1995). However, this recommended screening interval appears not to be well known and/or adhered to by patients and practitioners. Actually, a two-year interval appears to be the interval that practitioners more commonly recommend to their patients (INCa, 2007). In addition, it is not easy to obtain accurate information from women about the dates of their previous two smear tests. In this research, we therefore decided to use a two-year threshold to divide the adult female population into two subpopulations (2 years or less since their last smear test, or more than 2 years). In the SIRS survey, the date of the last screening test was self-reported by the women.

\section{$\underline{\text { Additional individual variables }}$}

In addition to age, we distinguished between French people born to two French parents, those born to at least one foreign parent, and foreigners (this variable is referred to as "origin" in the rest of this paper). The respondents' socioeconomic status was characterised by the following variables: the level of monthly household income (range: $50-10000 €$ per consumption unit; tertile values: 1 150/1 $900 € / \mathrm{CU}$ ), the level of education, and occupational status. To calculate the monthly household income, we added up the individual incomes of all the members of the household and divided this sum by an adjusted number of people living in that household, or consumption unit (CU). As for occupational status, we distinguished between those in the workforce, those unemployed, those retired, those at home, and students. Functional limitation was also investigated on the basis of a report of a severe limitation of at least six months' duration in performing activities people usually engage in. Also, the length of residence in the neighbourhood was examined in relation to the daily activities performed in the perceived neighbourhood. Lastly, health insurance status and whether the person was living in a couple relationship were studied in relation to participation in cervical screening. 


\section{$\underline{\text { Administrative neighbourhood variables }}$}

\section{Administrative neighbourhood delimitation}

Since the available data (collected in 2005) did not enable us to delimit the perceived neighbourhood, we had to set the boundaries of neighbourhood areas to be able to characterize the neighbourhood context. This delimitation involved defining (1) the shape and (2) the scale of these neighbourhood areas.

(1) The literature offers two distinct ways to delimit neighbourhoods in connection with health outcomes: as fixed and collective areas defined in a uniform manner for all the respondents or as areas centred on the respondents' residences (Chaix et al., 2005a). In this research, we based our neighbourhood delimitation on administrative census blocks (IRISs) because data on the number of practitioners were available only for these administrative units.

(2) To choose an administrative delimitation of a neighbourhood whose scale would correspond as best possible to the perceived neighbourhood of residents of the Paris metropolitan area, we used results from a survey carried out in 2006 and 2007 among 1124 residents of that area (14 neighbourhoods in Paris per se and 6 neighbourhoods in suburban areas). This survey attempted, among other things, to determine the scale used by respondents to define their neighbourhood of residence. An analysis showed that very few residents of the Paris metropolitan area $(0.1 \%)$ perceive their neighbourhood at a scale larger than a district (called, in French, an "arrondissement" within Paris and a "commune" outside Paris). A larger number of residents (20\%) considered their neighbourhood at the district scale. Actually, the vast majority of the residents $(75 \%)$ perceived their neighbourhood at a scale smaller than an urban district. Lastly, two other local areas were more rarely mentioned, with $5 \%$ of the residents considering their neighbourhood at the street or square scale, and $7 \%$ referring to equipment or a monument (Humain-Lamoure, 2008).

Urban districts appear to be too large to accurately depict perceived neighbourhoods, and census blocks appear to be too small. We therefore decided to create an intradistrict spatial unit by grouping census blocks together. We selected from a geographical information system (ESRI ArcMap 9.2) all the census blocks sharing a line segment with a given surveyed census block. After grouping these selected blocks together, we obtained 50 different administrative neighbourhood areas containing an average of 15,200 residents (range: 8,700-24,500), according to the last census (1999), with a mean area of $2.5 \mathrm{~km}^{2}$ (range: 0.3-13.5). These administrative neighbourhood areas were larger in the suburbs 
(mean area of $3.1 \mathrm{~km}^{2}$; range: $0.8-13.5$ ) than within Paris (mean area of $0.6 \mathrm{~km}^{2}$; range: $0.3-$ 1.6). Based on an example of four different locations (two within Paris and two outside), Figure 2 shows selected neighbourhood areas and helps visualise their shape, with the urban districts and census block boundaries, street networks and buildings superimposed.

Figure 2. Selected neighbourhood areas in the Paris metropolitan area
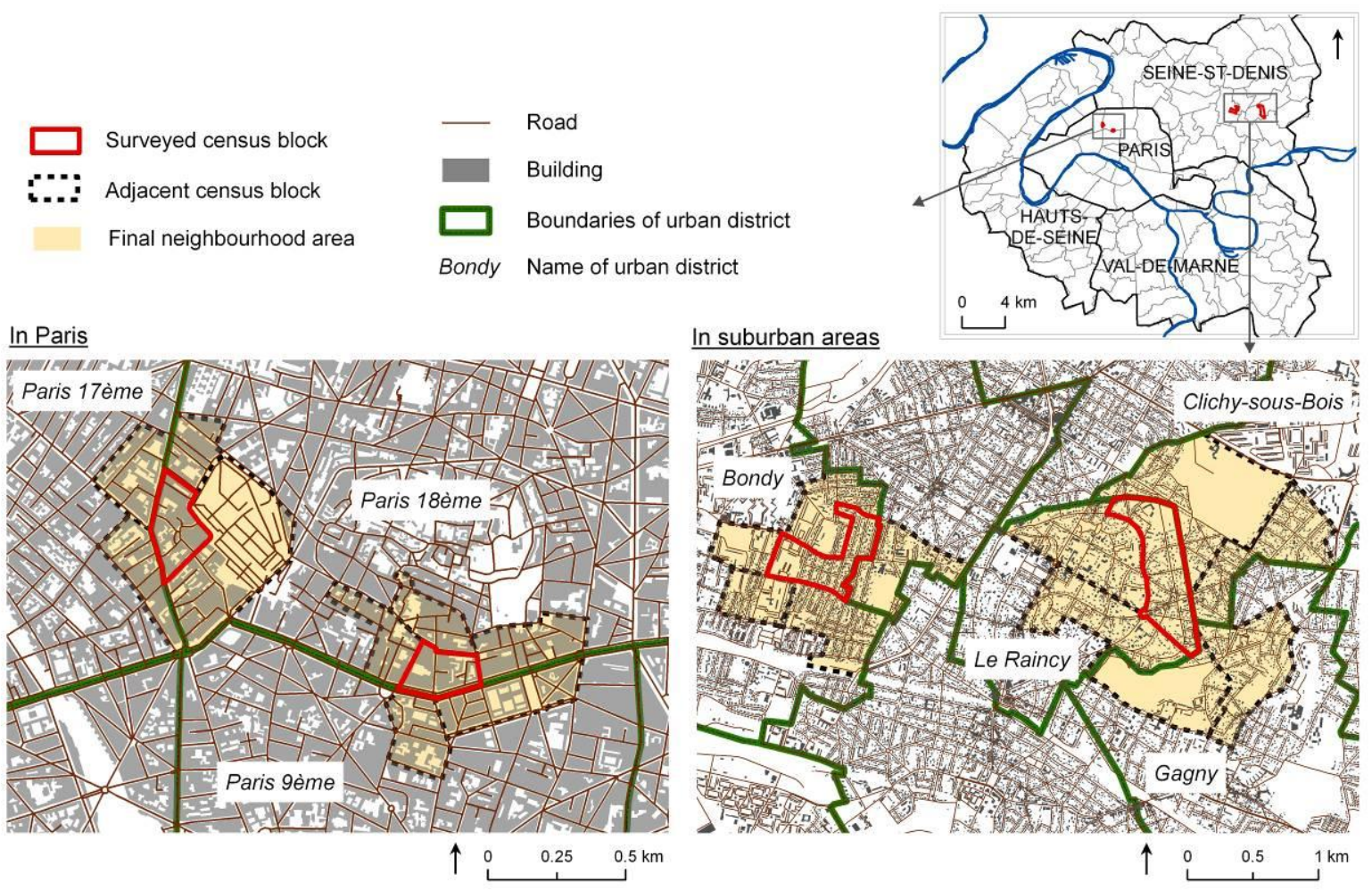

\section{Administrative neighbourhood characterization}

To characterize a neighbourhood of residence, we created five variables, as follows:

- The mean yearly household income. This figure was extracted from the 2005 income tax database (available from the French Department of National Revenue). It ranged from 8980 to $67330 € / \mathrm{CU}$ and was divided into tertiles (16 000 and $23000 € / \mathrm{CU}$ ) to define the socioeconomic profile of the neighbourhood's population.

- Shop density (food shops, supermarkets, restaurants, hairdressing salons, post offices, banks, clothing shops and bookshops). The number of shops was obtained from the 2007 services and amenities database (provided by INSEE, the French National Institute of Statistics and Economic Studies) and was divided by the surface area of the neighbourhood. Lastly, the shop density was divided in two groups, with a cutoff of 25 shops per $\mathrm{km}^{2}$ (range: 6-1170 shops per $\mathrm{km}^{2} ; 17$ neighbourhoods with fewer than 25 shops per $\mathrm{km}^{2}$ and 33 with more than 25 shops per $\mathrm{km}^{2}$ ). 
- The density of general practitioners and gynaecologists. The practitioner number was obtained from the INSEE database and was divided by the size of the population living in the area. Practitioner density, which ranged from 16 to $188 / 100000$ population, was divided into tertiles (59 and 110 practitioners/100 000 population).

- Location of the neighbourhood in the Paris metropolitan area. The neighbourhoods were in Paris per se (urban areas) or outside Paris (suburban areas).

- The proportion of people in the neighbourhood with a recent preventive consultation. We calculated the proportion of the respondents (including men and women) who reported having seen a physician in the previous 12 months for a preventive consultation (e.g., for a check-up, to see if everything was all right or for a vaccination). The proportion of individuals with a recent preventive consultation was determined for every surveyed census block in the SIRS dataset. It ranged from $10 \%$ to $43 \%$. We then divided it into tertiles $(25 \%, 33 \%)$.

The first three variables were based on the administrative neighbourhood area obtained by grouping adjacent census blocks together, while the last two were based only on the surveyed census blocks. These variables were introduced in statistical models to study their associations either with the concentration of daily activities in the perceived neighbourhood (mean income, shop density, and urban or suburban location) or with delayed cervical screening (mean income, urban or suburban location, practitioner density, and proportion of individuals with a recent preventive consultation).

\section{Statistical methods}

All the proportions and mean values presented in this paper were weighted to account for the complex sample design (specifically, the design effect associated with cluster sampling and the stratification that overrepresented the poorest neighbourhoods) and for the poststratification adjustment for age and gender according to the general population census data (using the "svy" command in Stata10 software). Significant differences between weighted proportions and between weighted means were measured by the Pearson chisquared test and an adjusted Wald test, respectively.

Multilevel linear regression models (using the "xtmixed" command in Stata10 software, specifying that the collected data were clustered by census block) were utilized to identify individual and residential neighbourhood characteristics associated with the concentration of daily activities in the perceived neighbourhood.

Multilevel logistic regression models (using the "xtmelogit" command in Stata10 software, specifying that the collected data were clustered by census block) were utilized to identify individual and residential neighbourhood characteristics associated with delayed cervical 
screening (> 2 years). In these models, between-area variation was measured using variance components.

The variance inflation factors (VIFs) were computed to check for colinearity between the independent variables in regression models. VIF values were overall under 3.0 (with slightly higher values -not exceeding 5.5- for age and occupational status), suggesting that multicollinearity was no a severe problem in these regression models.

To investigate whether the effects of neighbourhood characteristics in terms of delayed cervical screening differ across women's activity space, we calculated, in multilevel logistic regression models, the cross-level interaction term between the administrative-neighborhood characteristics and the concentration of daily activities in the perceived neighbourhood (divided into two subgroups). Lastly, we compared the odds ratios associated with the administrative-neighbourhood characteristics according to the women's activity space.

A p-value $<0.05$ was considered significant for all the statistical analyses presented.

\section{Results}

\section{Description of the survey population}

In the SIRS survey, $29 \%$ of the people contacted declined to answer, and $5 \%$ were excluded because they did not speak French $(3 \%)$ or because they were too sick to answer our questions (2\%) (Renahy et al., 2008). The final SIRS sample consisted of 3,023 persons, including 1,843 women.

The mean age of the SIRS population was 44.9 years (similar for men and women). As regards occupational status, $56 \%$ were in the workforce, $9 \%$ were unemployed, $19 \%$ were retired, $8 \%$ were at home, and $7 \%$ were students. The proportion of individuals in the workforce was statistically higher for men $(62 \%)$ than for women $(52 \% ; p<0.01)$, and the proportion of individuals at home was statistically higher for women (13\%) than for men (2\%; $\mathrm{p}<0.01$ ). As for the level of education, $51 \%$ had a postsecondary education, while $10 \%$ had a primary school education or less (with no statistical differences between men and women). With regard to origin, $68 \%$ were French, born to two French parents; $18 \%$ were French, born to at least one foreign parent; and $14 \%$ were foreigners.

Of the 1,843 women surveyed, 66 were not asked about cervical screening because they had had a hysterectomy in the past, and 3 others did not answer this question. Therefore, the sample for studying cervical screening in the Paris metropolitan area consisted of 1,774 women (aged 18 to 97 years). 


\section{Description of the measure of activity space}

Table 1 presents, for each of the five selected daily activities, the number and proportion of respondents who reported doing it mainly within their neighbourhood of residence, both within and outside their neighbourhood of residence, or mainly outside. It can be seen that the majority of the respondents reported engaging in domestic activities (going food shopping and using services) within their neighbourhood of residence and engaging in social and leisure activities (going to a restaurant or café, going for a walk and meeting friends) partly or mainly outside their neighbourhood. Scores measuring the concentration of daily activities in the perceived neighbourhood were not available for the 12 respondents ( 8 of whom were women) who did not provide answers regarding the five activities in question.

Table 1. Number and percentage of Paris metropolitan area residents who reported doing their daily activities within their perceived neighbourhood of residence in 2005.

\begin{tabular}{|c|c|c|c|c|}
\hline & \multicolumn{4}{|c|}{ Number (and percentage ${ }^{\star}$ ) of people who reported doing the following activities } \\
\hline & $\begin{array}{l}\text { Mainly within their } \\
\text { neighbourhood of } \\
\text { residence }\end{array}$ & $\begin{array}{l}\text { Both within and } \\
\text { outside their } \\
\text { neighbourhood of } \\
\text { residence }\end{array}$ & $\begin{array}{l}\text { Mainly outside their } \\
\text { neighbourhood of } \\
\text { residence }\end{array}$ & $\begin{array}{c}\text { Activity not } \\
\text { reported }\end{array}$ \\
\hline Food shopping & $1532(54)$ & $770(24)$ & $664(19)$ & $57(2)$ \\
\hline Using services (post office, bank, etc.) & $1759(61)$ & $450(14)$ & $776(24)$ & $38(1)$ \\
\hline Going for a walk & $754(25)$ & $966(34)$ & $1,132(36)$ & $171(5)$ \\
\hline Meeting friends & $529(16)$ & $1,074(38)$ & $1,232(41)$ & $188(5)$ \\
\hline Going to a restaurant or café & $448(16)$ & $553(20)$ & $1,426(47)$ & $596(16)$ \\
\hline
\end{tabular}

* Complex sample design taken into account when calculating the percentage.

The concentration scores were well distributed among the general population of the Paris metropolitan area (Figure 3). The (weighted) mean score was 0.51 [95\% Cl: 0.47-0.55].

To isolate people who reported doing the vast majority of their daily activities within their perceived neighbourhood, we used grouped together the respondents with a score greater than or equal to 0.8 . They were those who reported doing either (a) every activity within their perceived neighbourhood of residence, (b) one or two activities both within and outside their perceived neighbourhood, or (c) only one activity mainly outside their perceived neighbourhood of residence. Lastly, 520 of the 3,011 individuals surveyed (17.5\%) were thus considered as having an activity space substantially limited to their perceived neighbourhood, while 2,491 (82.5\%) were considered as having an activity space larger than their perceived neighbourhood. Of the 1,768 women studied with regard to their last cervical screening test (and for whom daily activity concentration scores were available), 313 (19.6\%) and 1455 (80.4\%) were considered, respectively, as having an activity space limited to or larger than their perceived neighbourhood. 
Figure 3. Histogram of the distribution of the score measuring the concentration of daily activities in the perceived neighbourhood

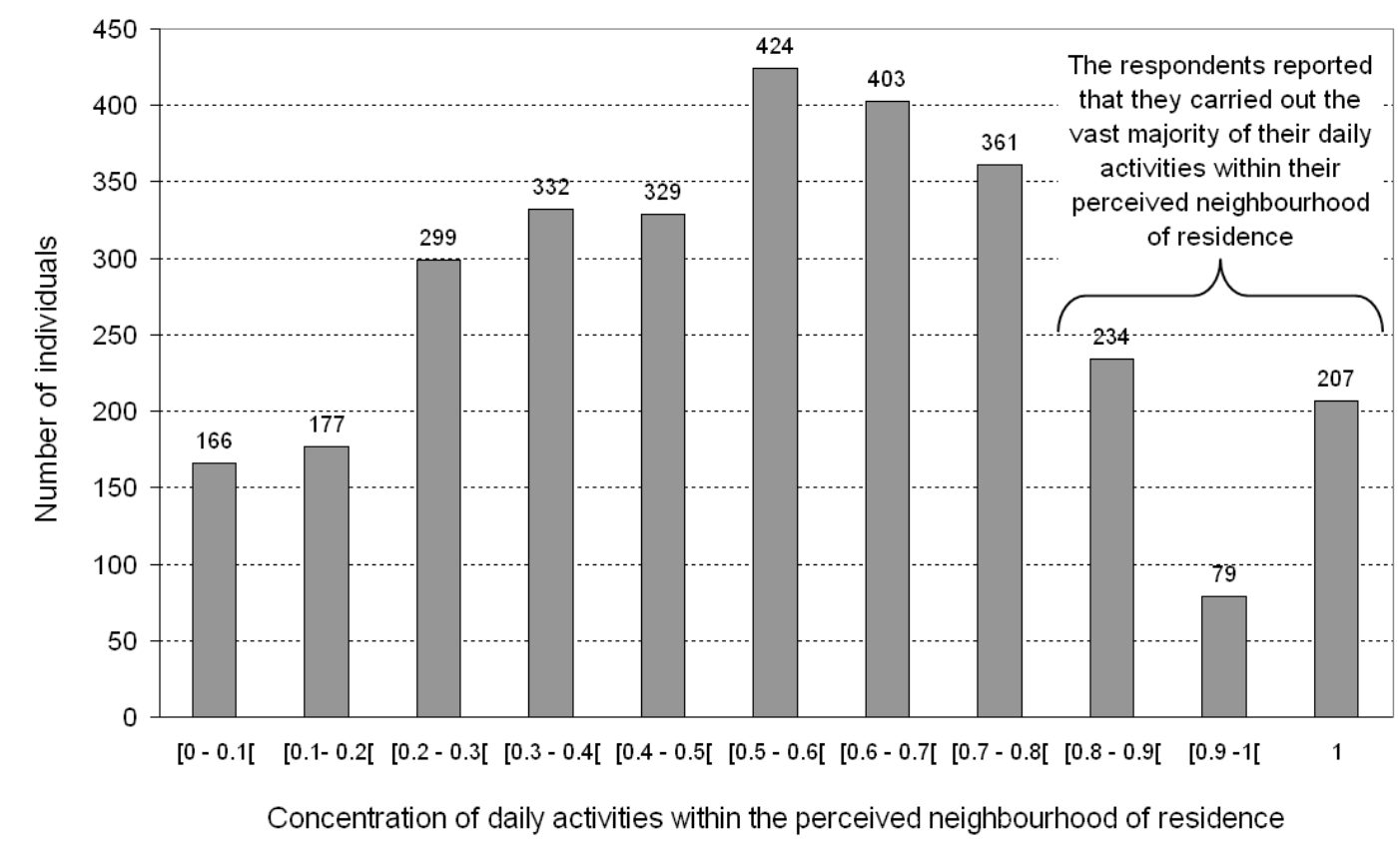

The concentration of daily activities within the perceived neighbourhood: a component of social status and neighbourhood structures

Comparing the (weighted) concentration score of daily activities in the perceived neighbourhood between the subpopulations (Table 2), we found that there was no statistical difference between men and women (a mean score of 0.52 and 0.50 , respectively). With a mean score of 0.60 , people aged 60 years or older reported an activity space statistically centred more within their neighbourhood than did younger people. We also observed a statistical difference in the mean concentration scores according to origin, the level of education, occupational status, the length of residence in the neighbourhood, and functional limitation status. Lastly, there was no statistical difference between concentration scores according to household income.

In the multilevel linear regression model, several individual characteristics were statistically associated with the concentration of daily activities in the perceived neighbourhood (Table 2). Being a foreigner, having a low level of education, living in a low-income household, being unemployed, retired or at home, having lived in the neighbourhood for more than 20 years and being physically limited were all positively associated with an activity space centred more within the perceived neighbourhood. On the other hand, when these characteristics were taken into account, neither gender nor age was significantly associated with this measure of activity space. After the individual sociodemographic characteristics were 
controlled for in the multilevel models, living in Paris, living in a neighbourhood with a high shop density and with a high mean income were all positively associated with an activity space centred more within the perceived neighbourhood. Lastly, we observed that individual and neighbourhood factors associated with this measure of activity space were broadly similar in the general population and in the female-only population.

Table 2. Individual and neighbourhood factors for the concentration of daily activities within the neighbourhood of residence among the population in the Paris metropolitan area (2005), as determined by multilevel linear regression

\begin{tabular}{|c|c|c|c|c|c|c|c|}
\hline & \multirow{2}{*}{$\begin{array}{l}\text { Score measuring the concentration of daily } \\
\text { activities in the perceived neighbourhood } \\
(0 \text { to } 1)\end{array}$} & \multicolumn{3}{|c|}{$\begin{array}{c}\text { General population } \\
n=3011\end{array}$} & \multicolumn{3}{|c|}{$\begin{array}{c}\text { Female population } \\
n=1835\end{array}$} \\
\hline & & $\begin{array}{l}\mathrm{Me} \\
\mathrm{sco}\end{array}$ & & Coef. $(95 \% \mathrm{Cl})$ & & & Coef. $(95 \% \mathrm{Cl})$ \\
\hline \multirow{3}{*}{ 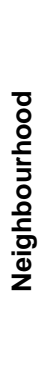 } & $\begin{array}{l}\text { Mean neighbourhood income (per } \\
\text { household, per CU) } \\
\text { Low } \\
\text { Middle } \\
\text { High }\end{array}$ & $\begin{array}{l}0.39 \\
0.51 \\
0.55\end{array}$ & * & $\begin{array}{c}\text { Ref. } \\
.073(-.002 \text { to } .144) \\
.151(.077 \text { to } .225)^{\star}\end{array}$ & $\begin{array}{l}0.39 \\
0.51 \\
0.57\end{array}$ & * & $\begin{array}{c}\text { Ref. } \\
.074(.000 \text { to } .147)^{*} \\
.167(.090 \text { to } .243)^{*}\end{array}$ \\
\hline & $\begin{array}{l}\text { Neighbourhood shop density (per km²) } \\
\text { Low } \\
\text { High }\end{array}$ & $\begin{array}{l}0.43 \\
0.54\end{array}$ & * & $\begin{array}{c}\text { Ref. } \\
.075(.010 \text { to } .140)^{\star}\end{array}$ & $\begin{array}{l}0.45 \\
0.55\end{array}$ & * & $\begin{array}{c}\text { Ref. } \\
.064(-.004 \text { to } .131)\end{array}$ \\
\hline & $\begin{array}{l}\text { Location } \\
\text { Suburban } \\
\text { In Paris }\end{array}$ & $\begin{array}{l}0.45 \\
0.64\end{array}$ & * & $\begin{array}{c}\text { Ref. } \\
.135(.061 \text { to } .208)^{\star}\end{array}$ & $\begin{array}{l}0.46 \\
0.66\end{array}$ & * & $\begin{array}{c}\text { Ref. } \\
.148(.072 \text { to } .223)^{\star}\end{array}$ \\
\hline \multirow{8}{*}{$\frac{\bar{\pi}}{\stackrel{\text { go }}{2}}$} & $\begin{array}{l}\text { Sex } \\
\text { Menen }\end{array}$ & $\begin{array}{l}0.50 \\
0.52\end{array}$ & NS & $\begin{array}{c}\text { Ref. } \\
.012(-.005 \text { to } .029)\end{array}$ & - & - & - \\
\hline & $\begin{array}{l}\text { Age } \\
18-29 \text { years } \\
30-44 \text { years } \\
45-59 \text { years } \\
\geq 60 \text { years }\end{array}$ & $\begin{array}{l}0.47 \\
0.49 \\
0.50 \\
0.60\end{array}$ & * & $\begin{array}{c}\text { Ref. } \\
.024(-.003 \text { to } .051) \\
.007(-.022 \text { to } 0.036) \\
.037(-.006 \text { to } .081)\end{array}$ & $\begin{array}{l}0.48 \\
0.50 \\
0.51 \\
0.60\end{array}$ & * & $\begin{array}{c}\text { Ref. } \\
.024(-.011 \text { to } .059) \\
.000(-.038 \text { to } 0.038) \\
.022(-.035 \text { to } .079)\end{array}$ \\
\hline & $\begin{array}{l}\text { Origin } \\
\text { French, born to French parents } \\
\text { French, born to at least one foreign parent } \\
\text { Foreigners }\end{array}$ & $\begin{array}{l}0.51 \\
0.48 \\
0.55\end{array}$ & * & $\begin{array}{c}\text { Ref. } \\
.013(-.009 \text { to } .036) \\
.059(.033 \text { to } .086)^{\star}\end{array}$ & $\begin{array}{l}0.52 \\
0.48 \\
0.57\end{array}$ & $N S$ & $\begin{array}{c}\text { Ref. } \\
.032(.003 \text { to } .061)^{\star} \\
.068(.033 \text { to } .104)^{\star}\end{array}$ \\
\hline & $\begin{array}{l}\text { Level of education } \\
\text { Postsecondary } \\
\text { Secondary school - } 2 \\
\text { Secondary school - } 1 \\
\text { None or primary school }\end{array}$ & $\begin{array}{l}0.50 \\
0.48 \\
0.52 \\
0.61\end{array}$ & * & $\begin{array}{c}\text { Ref. } \\
.027(.004 \text { to } .050)^{\star} \\
.033(.007 \text { to } .059)^{\star} \\
.110(.077 \text { to } .143)^{\star}\end{array}$ & $\begin{array}{l}0.51 \\
0.51 \\
0.52 \\
0.62\end{array}$ & * & $\begin{array}{c}\text { Ref. } \\
.031(.001 \text { to } .061)^{\star} \\
.027(-.006 \text { to } .061) \\
.116(.075 \text { to } .158)^{\star}\end{array}$ \\
\hline & $\begin{array}{l}\text { Household income (per CU) } \\
\text { High } \\
\text { Middle } \\
\text { Low }\end{array}$ & $\begin{array}{l}0.52 \\
0.49 \\
0.53\end{array}$ & $N S$ & $\begin{array}{c}\text { Ref. } \\
.022(.000 \text { to } .045)^{\star} \\
.074(.047 \text { to } .101)^{\star}\end{array}$ & $\begin{array}{l}0.53 \\
0.50 \\
0.54\end{array}$ & $N S$ & $\begin{array}{c}\text { Ref. } \\
.017(-.012 \text { to } .046) \\
.068(.034 \text { to } .103)^{*}\end{array}$ \\
\hline & $\begin{array}{l}\text { Occupational status } \\
\text { Working } \\
\text { Unemployed } \\
\text { Retired } \\
\text { At home } \\
\text { Student }\end{array}$ & $\begin{array}{l}0.47 \\
0.54 \\
0.61 \\
0.58 \\
0.44\end{array}$ & * & $\begin{array}{c}\text { Ref. } \\
.063(.005 \text { to } .067)^{\star} \\
.060(.022 \text { to } .099)^{\star} \\
.056(.023 \text { to } .088)^{\star} \\
-.025(-.070 \text { to } .020)\end{array}$ & $\begin{array}{l}0.49 \\
0.53 \\
0.60 \\
0.58 \\
0.43\end{array}$ & * & $\begin{array}{c}\text { Ref. } \\
.015(-.026 \text { to } .055) \\
.065(.015 \text { to } .115)^{\star} \\
.049(.011 \text { to } .087)^{\star} \\
-.047(-.106 \text { to } .011)\end{array}$ \\
\hline & $\begin{array}{l}\text { Length of residence in the } \\
\text { neighbourhood } \\
<20 \text { years } \\
\geq 20 \text { years }\end{array}$ & $\begin{array}{l}0.49 \\
0.55\end{array}$ & * & $\begin{array}{c}\text { Ref. } \\
.027(.006 \text { to } .048)^{\star}\end{array}$ & $\begin{array}{l}0.50 \\
0.56\end{array}$ & * & $\begin{array}{c}\text { Ref. } \\
.022(-.005 \text { to } .049)\end{array}$ \\
\hline & $\begin{array}{l}\text { Severe functional limitation } \\
\text { No } \\
\text { Yes }\end{array}$ & $\begin{array}{l}0.50 \\
0.64\end{array}$ & * & $\begin{array}{c}\text { Ref. } \\
.078(.045 \text { to } .112)^{\star}\end{array}$ & $\begin{array}{l}0.51 \\
0.63\end{array}$ & * & $\begin{array}{c}\text { Ref. } \\
.059(.016 \text { to } .101)^{\star}\end{array}$ \\
\hline
\end{tabular}

${ }^{1}$ Complex sample design taken into account when calculating the mean.

${ }^{*} p<0.05 ;$ NS: Not significant ( $\left.p>0.05\right)$ 


\section{Concentration of daily activities within the perceived neighbourhood and cervical screening}

In all, one-fourth of the women (25.7\%) reported not having had a cervical screening test during the previous two years. The mean concentration of daily activities in the perceived neighbourhood was 0.51 [95\% Cl: 0.47-0.55] for women who had recently had a test and 0.55 [95\% Cl: $0.49-0.61]$ for those with a delay in being tested. These scores were not statistically different $(p=0.10)$. After taking into account only the individual characteristics (age, origin, level of education, health insurance status, household income, occupational status, couple relationship status and functional limitation status), we observed that the concentration score was not statistically associated with delayed cervical screening (OR=1.46; 95\% Cl=0.91-2.334. See Model 1 in Table 3).

After introducing the neighbourhood characteristics into the model, in addition to individual characteristics, we observed that the concentration of daily activities in the perceived neighbourhood was statistically associated with delayed cervical screening, regardless of the administrative-neighbourhood variables introduced into the model, not only the location in the Paris metropolitan area (Model 2), but also the practitioner density (Model 3a), the proportion of residents with a recent preventive consultation (Model $3 b$ ) and the mean neighbourhood income (Model 3c). The more the women reported concentrating their daily activities within their neighbourhood of residence, the more they had delayed undergoing cervical screening (e.g., $\mathrm{OR}=1.93 ; 95 \% \mathrm{Cl}=1.20-3.11$. See Model 3c). The association between the concentration score and delayed cervical screening was also statistically significant when these four neighbourhood characteristics were introduced into the model together (Model 4).

\section{Individual characteristics and cervical screening}

Several other individual characteristics were statistically associated with delayed cervical screening (Table 3). Being less than 30 or more than 60 years of age, being a foreigner, not being fully covered by health insurance, being a student, not living in a couple relationship and being physically limited were all positively associated with delayed cervical screening in the multivariate analysis. 
Table 3. Individual and neighbourhood risk factors for not having undergone cervical screening in the previous two years in the population in the Paris metropolitan area (2005), as determined by multilevel logistic regression

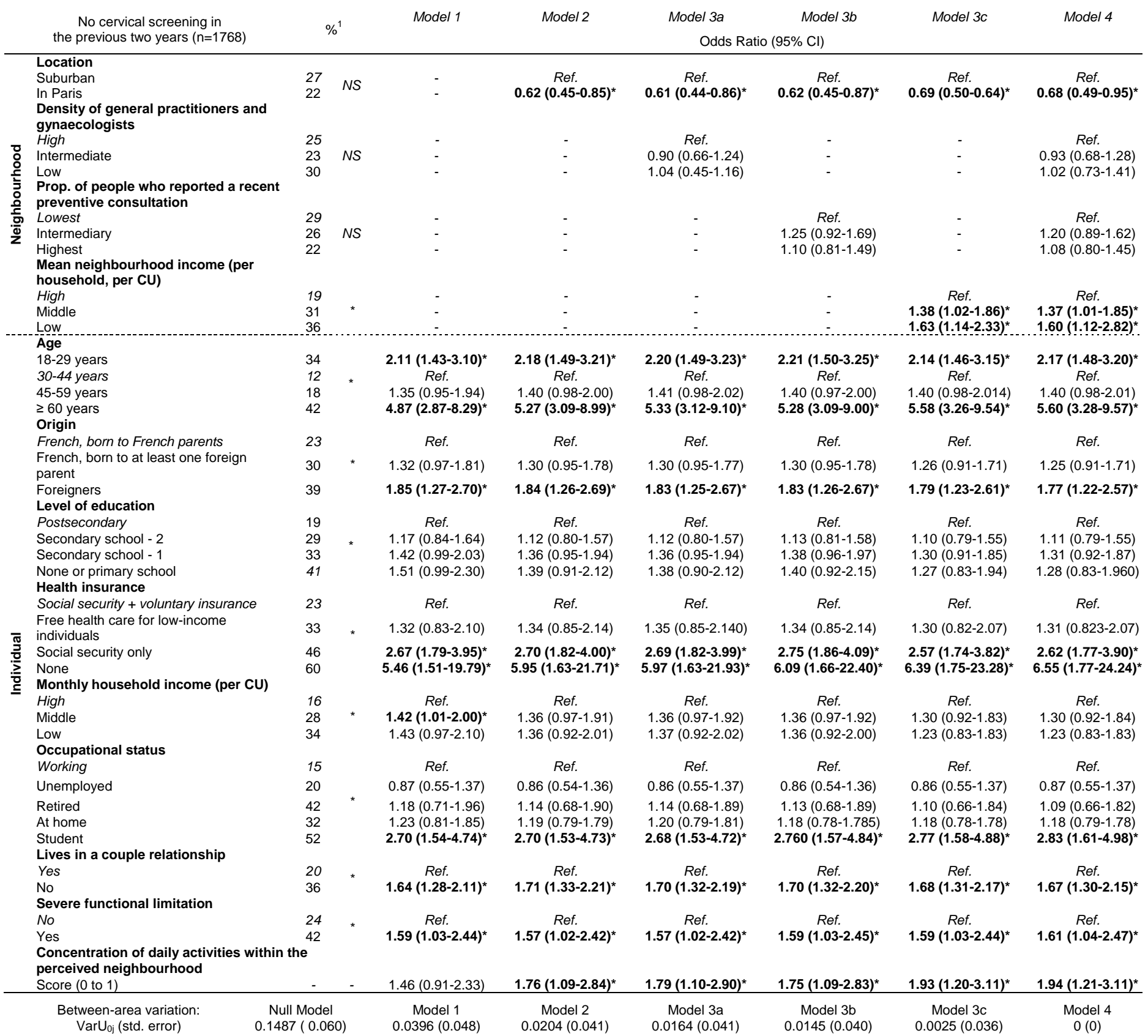

${ }^{1}$ Proportion of women who reported not having undergone cervical screening during the previous two years (complex sample design taken into account).

${ }^{*} p<0.05 ;$ NS: Not significant ( $\left.p>0.05\right)$

\section{Administrative-neighbourhood characteristics and cervical screening}

It can be seen from Table 3 that neither a low practitioner density nor a low proportion of people with a recent preventive consultation was statistically associated with delayed cervical screening $(\mathrm{OR}=1.04 ; 95 \% \mathrm{Cl}=0.45-1.16$ in Model $3 \mathrm{a}$, and $\mathrm{OR}=1.10 ; 95 \% \mathrm{Cl}=0.81-1.49$ in Model 3b). On the other hand, the mean neighbourhood income was statistically associated 
with delayed cervical screening when introduced into the multilevel models: women had a greater likelihood of delayed cervical screening if they were living in a neighbourhood where the mean income was low ( $\mathrm{OR}=1.63 ; 95 \% \mathrm{Cl}=1.14-2.33$; see Model 3c). Furthermore, women living in a neighbourhood in Paris per se had a lower likelihood of delayed cervical screening than those living in a suburban area, regardless of the other administrativeneighbourhood variables introduced in the model $(\mathrm{OR}=0.62 ; 95 \% \mathrm{Cl}=0.45-0.84$; see Model 3b, for example).

When these four neighbourhood variables were introduced into the model together, we observed that a low mean neighbourhood income and location in Paris per se remained both significantly associated with delayed cervical screening $(\mathrm{OR}=1.60 ; 95 \% \mathrm{Cl}=1.12-2.82$, and $\mathrm{OR}=0.68 ; 95 \% \mathrm{Cl}=0.49-0.95$, respectively, in Model 4).

\section{Spatial disparities in cervical screening in the Paris metropolitan area}

Depending on the census block surveyed, the proportion of women with delayed cervical screening varied from $11 \%$ to $58 \%$, as shown in Figure 4 .

Figure 4. Spatial disparities in cervical screening in the Paris metropolitan area in 2005

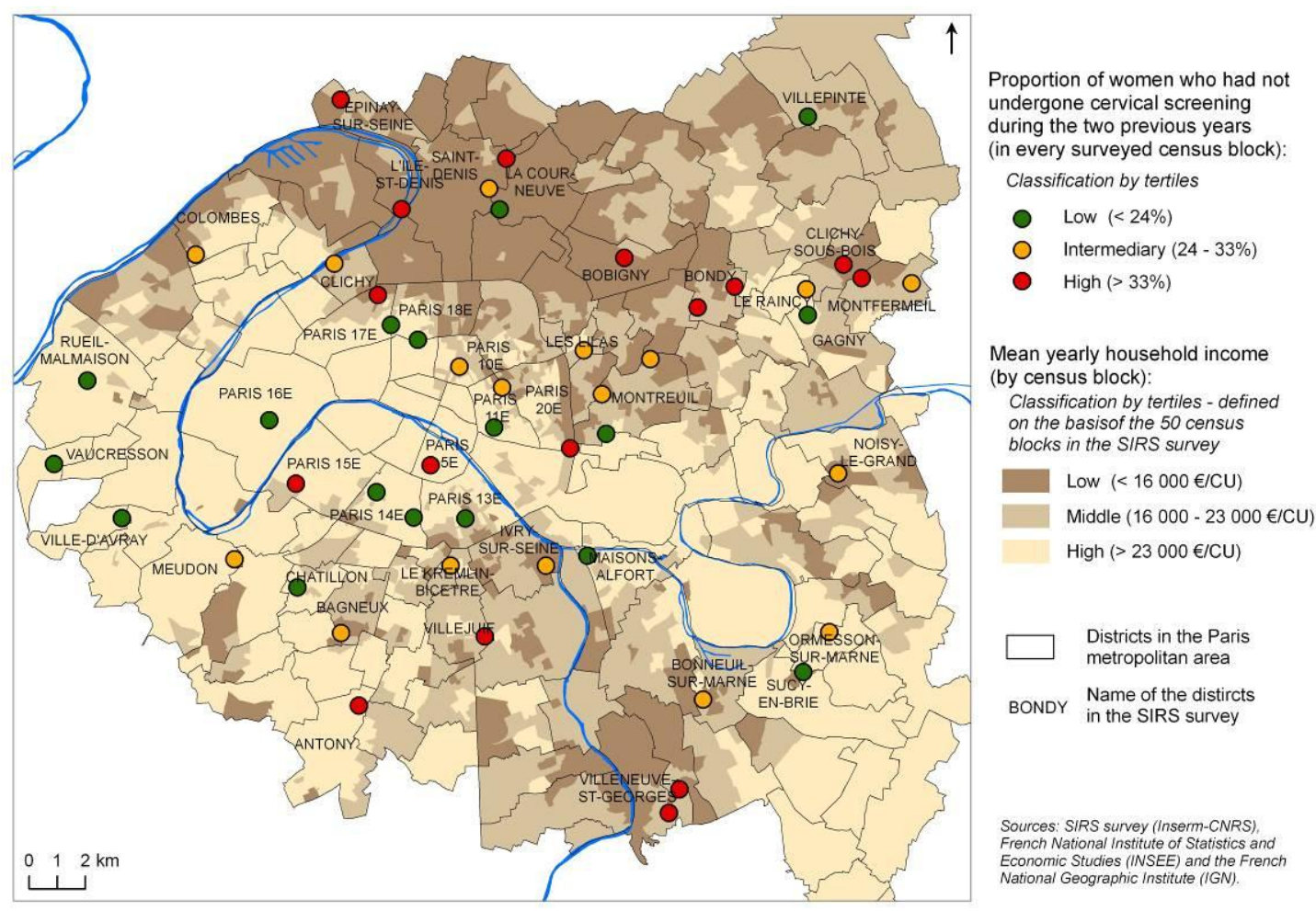

The crude between-area variation $\left(\operatorname{Var} \mathrm{U}_{0 \mathrm{j}}=0.149\right.$; standard error $\left.=0.060\right)$ was statistically significant, which indicates that there were spatial disparities in cervical screening between the 50 census blocks surveyed in the Paris metropolitan area (Table 3 ). When the individual characteristics were added to the model (Model 1), the between-area variation decreased 
considerably, but it remained statistically positive, which indicates that spatial variations in participation in cervical screening are not fully explained. When location in the Paris metropolitan area, practitioner density or the proportion of people with a recent preventive consultation were included in the model, the between-area variation decreased even more (Models 2, 3a and 3b). However, it is only when the mean neighbourhood income was taken into account that this variation strongly decreased (Model 3c), and it even became statistically null when the mean neighbourhood income was added to the model with the other neighbourhood characteristics (Model 4).

Significant interaction between measure of activity space and administrative-neighbourhood characteristics on delayed cervical screening

Cross-level interactions between concentration of daily activities in the perceived neighbourhood and administrative-neighbourhood characteristics were calculated in regression models (after adjustment for age, occupational status, health insurance status, couple relationship status and functional limitation status). They were statistically significant for two of the four neighbourhood variables (Table 4). We observed significant cross-level interaction for practitioner density and the proportion of people with a recent preventive consultation, i.e., the neighbourhood variables that were not statistically associated with delayed cervical screening in the general population.

In the subpopulation models (Table 4), we observed that living in a neighbourhood with a low practitioner density significantly increased the likelihood ( $\mathrm{OR}=2.91 ; 95 \% \mathrm{Cl}=1.43-5.92)$ of delayed cervical screening among the women with an activity space limited to their perceived neighbourhood, while it did not significantly impact the likelihood $(\mathrm{OR}=1.19 ; 95 \% \mathrm{Cl}=0.85$ 1.67) of delayed cervical screening among those with an activity space larger than their perceived neighbourhood.

Similarly, we observed that living in a neighbourhood with a low proportion of people with a recent preventive consultation statistically increased the likelihood $(\mathrm{OR}=2.42 ; 95 \% \mathrm{Cl}=1.30$ 4.48) of delayed cervical screening among the women with an activity space limited to their perceived neighbourhood, while it did not significantly impact the likelihood (OR=1.00;95\% $\mathrm{Cl}=0.71-1.417$ ) of delayed cervical screening among those with an activity space larger than their perceived neighbourhood.

On the other hand, we did not observe a significant cross-level interaction for mean neighbourhood income or neighbourhood location in the Paris metropolitan area (Table 4), i.e., the variables that were statistically associated with delayed cervical screening in the general population. 
Table 4. Effect of residential neighbourhood characteristics on delayed cervical screening (after adjustment for age, occupational status, health insurance status, couple relationship status, and functional limitation status), as determined from the multilevel logistic regression model for two subpopulations (according to the concentration of their daily activities within their perceived neighbourhood).

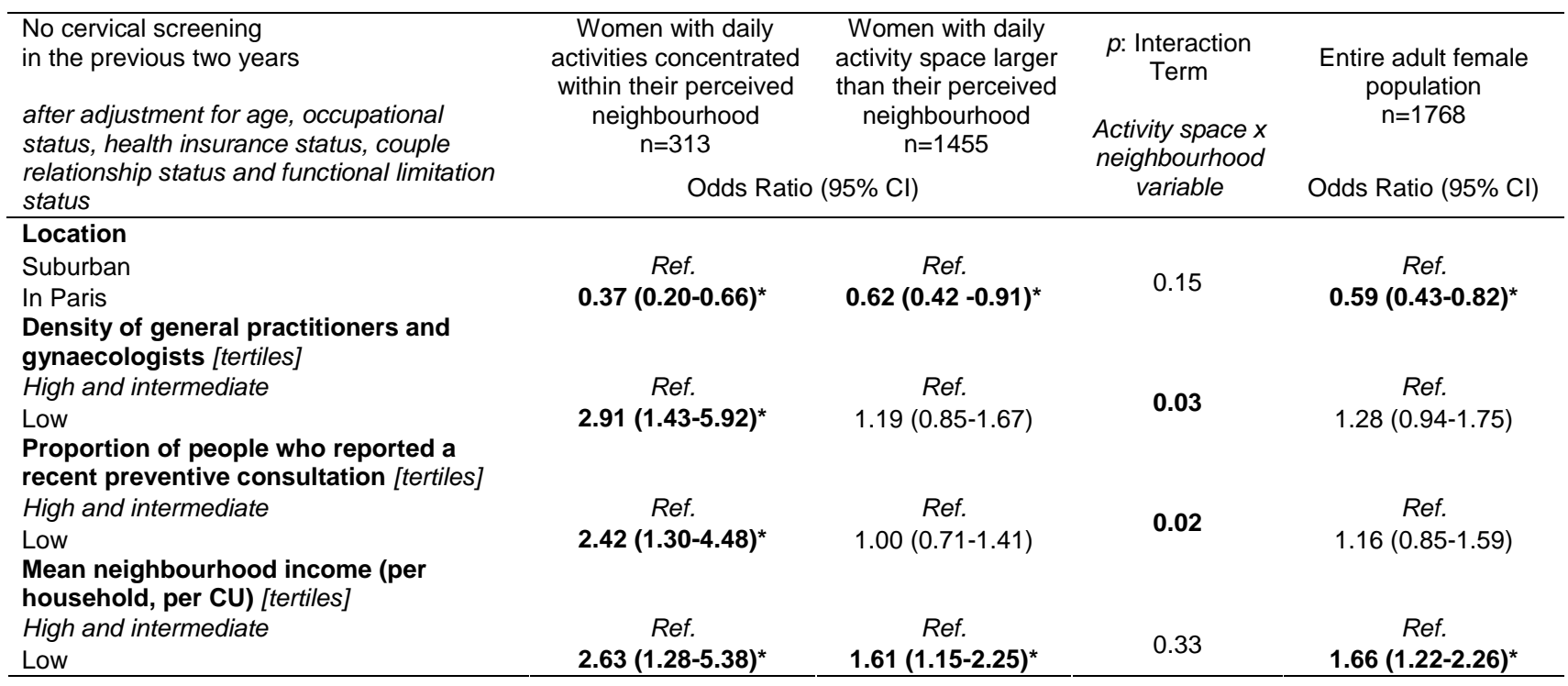

${ }^{*} p<0.05$

\section{Discussion}

\section{Self-reporting of cervical screening}

In our study, the date of the last cervical screening test was self-reported by the women and there may be several reasons for doubting the accuracy with which women report cervical screening histories. The self-reporting of Pap smear tests relies on remembering events dating back many years, with less recent events being subject to greater memory biases. There is also a social desirability bias, i.e., a certain degree of social pressure to report in questionnaires a behaviour that conforms to accepted health norms (Bowman et al., 1991). Yet, we postulated that for cervical screening tests, such biases may be less problematic than for other, more sensitive health behaviours.

\section{Organization of cervical screening in France}

In the Paris metropolitan area (and in the vast majority of France's departments), cervical screening is of the opportunistic type only, since there is no organized cervical screening program. Women are thus free to decide when and where they want to have their Pap smear test. Consequently, the location of cervical cancer screening is not determined by the national health system: women can choose to have their screening test performed close to or far from their place of residence. It was therefore relevant to study the cross-implication of 
the measure of activity space and neighbourhood practitioner density for participation in cervical screening.

In France, smear tests are not fully covered by the social health security system, which could explain why women without voluntary insurance were found, in this study, to be more likely not to have undergone cervical screening during the previous two years.

Although cervical screening is recommended in France only for women from 25 to 65 years of age, we decided not to set a lower or upper age limit in our sample, since it is known that younger and older women undergo also this screening test (INCa, 2007). The results presented in this paper are consistent with the national recommendations, as younger and older women had a greater likelihood of not having undergone cervical screening during the previous two years.

\section{About the measure of activity space}

We proposed above a simplified measure of activity space based on the respondents' statements. This self-definition of activity space was associated with individual and neighbourhood profiles because daily mobility may vary according to individual and neighbourhood characteristics and because individual and neighbourhood characteristics may also influence the size of the perceived neighbourhood. The social sciences have recognized that perceived neighbourhood boundaries are specific to every inhabitant, even for those living in close proximity (Coulton et al., 2001). In this paper, we observed that foreigners, people with a low level of education and those living in a low-income household reported daily activities that were centred more within their perceived neighbourhood. These individuals may have reported that they concentrated their activities within their neighbourhood (i) because their daily mobility was actually spatially limited and/or (ii) because they tended to perceive their neighbourhood as being larger than the other individuals did. This second possibility seems less likely since certain papers have pointed out that recent immigrants, people who are less educated and those with a lower income are more likely to view their neighbourhood as smaller than do other respondents (Guest and Lee, 1984; Lee and Campbell, 1997; Logan and Collver, 1983; Sastry et al., 2002).

Whatever, the available data did not enable us to delimit individual perceived neighbourhoods or identify the factors specifically associated with the size of a perceived neighbourhood. Consequently, it was not possible, in this paper, to identify (i) the factors directly associated with the spatial extent of daily mobility or (ii) those associated with the size of the perceived neighbourhood. This is the main limitation of the simplified measure of activity space proposed in this paper.

In addition, it can be assumed that as a cognitive construct, the perceived neighbourhood can vary according the spatial extent of daily activities, and vice versa. Behavioural 
geographers do, in fact, point out that "perceived territories act to constrain and direct an individual's trip though space" (Golledge and Stimson, 1997) and that "activity spaces represent an important process though which we gain information and attachment to our environment" (Jakle et al., 1976). The identification of territories and movement in the environment may thus be closely linked (Golledge and Stimson, 1997). Consequently, the spatial extent of daily mobility and the spatial extent of the perceived neighbourhood of residence may interact with each other (see the conceptual framework presented in Figure 1).

\section{About the administrative neighbourhood delimitation}

We chose to delimit neighbourhood areas as a group of adjacent census blocks so that they would correspond as best possible to the scale of the perceived neighbourhood of the majority of the residents of the Paris metropolitan area (Humain-Lamoure, 2008). When we calculated the size of these administrative neighbourhood areas, we observed that they were larger in the suburban areas than in Paris per se (mean area of $3.1 \mathrm{~km}^{2}$ and $0.6 \mathrm{~km}^{2}$, respectively). This difference appeared to correspond to the difference in perceivedneighbourhood size, since suburbanites tend to consider their neighbourhood at a larger scale than do city dwellers, as shown recently by Humain-Lamoure in the Paris metropolitan area (2008) and previously by Haney and Knowles (1978). To take into account differences in the perceived neighbourhoods according urban and suburban location, we controlled for neighbourhood location in the Paris metropolitan area in the regression models.

Unfortunately, it was not possible in this research to examine more closely the spatial correspondence between individual perceived neighbourhoods and our administrative territorial neighbourhood delimitation. This spatial correspondence will be studied as soon as data concerning the boundaries of perceived neighbourhood (collected in 2009-2010 within the framework of the SIRS cohort) are available.

Bias resulting from potential spatial incongruity between the perceived neighbourhoods and $\underline{\text { the administrative neighbourhoods }}$

The inability to examine the spatial correspondence between the perceived neighbourhoods and the administrative neighbourhoods may have led to a misinterpretation of personal exposure to the neighbourhood of residence for certain individuals. Depending on the individual, the perceived neighbourhood may be the same, smaller or larger than the administrative neighbourhood. Actually, there may be two types of misinterpretation of personal exposure to the neighbourhood of residence:

- On the one hand, a person whose perceived neighbourhood was smaller than the administratively delimited neighbourhood and whose activities were clustered just beyond 
the boundary of his/her perceived neighbourhood was categorized as having an activity space larger than his/her perceived neighbourhood and was consequently wrongly considered slightly exposed to the administrative-neighbourhood characteristics (bias no. $1)$.

- On the other hand, a person whose perceived neighbourhood was larger than the administratively delimited neighbourhood and whose activities took place mainly within the perceived neighbourhood was categorized as having an activity space centred within his/her perceived neighbourhood and was consequently wrongly considered as highly exposed to the administrative-neighbourhood characteristics (bias no. 2).

These two types of misclassification are presently impossible to quantify. Furthermore, these misclassifications cannot be dismissed as random, as they probably vary according to the neighbourhood and individual factors (see above). However, we can assume that they were relatively uncommon, since they did not hinder the model's ability to detect cross-level interaction between administrative-neighbourhood characteristics and activity space within perceived neighbourhood.

\section{Omission of the workplace in the measure of activity space}

Employment is a routine activity that has been found to have an influence on the spatial extent of his/her activity space (Golledge and Stimson, 1997). However, in this research, employment was not among the activities included in the measure of activity space. This information was not available, since the people surveyed were not asked to situate their work activities within or outside what they perceived as their neighbourhood of residence. Workplace omission thus constitutes a limitation of our measure of activity space. However, we could postulate that we accounted for workplace exposure through the domestic and social activities done within the workplace neighbourhood. Actually, our measure of activity space included "discretionary" activities - whose location is intentionally chosen by people and excluded "obligatory" activities, such as work, whose location is not chosen (Golledge and Stimson, 1997).

Double and opposite effect of poverty on the concentration of daily activities in the perceived neighbourhood

The results of the multilevel linear regression (Table 2) indicate that poor people and those living in more privileged neighbourhoods (in terms of the shop density and the mean neighbourhood income) are both more inclined to concentrate their daily activities within their perceived neighbourhood. In other words, at the individual level, poverty leads to a higher concentration of daily activities within the perceived neighbourhood, while neighbourhood deprivation leads to a lower concentration of daily activities within the perceived 
neighbourhood. This apparent contradiction is easily explainable. People living in privileged and well-equipped neighbourhoods do not necessarily need to travel to another place to access urban facilities, such as food shops, services, restaurants and recreational sites. On the other hand, wealthier people with financial, cultural and social capital have more power over space (Bourdieu, 2000). Overall, they have a wider "spatial capital", that is, a greater potential for mobility, or what Kaufmann (2002) refers to as "motility", even if they do not necessarily exercise this potential.

The fact that the statistical association between income and activity space varied in opposite directions when individual income or the mean neighbourhood income was considered was useful for discussions of the distinction between people and places, and composition and context (Macintyre and Ellaway, 2003). In this multilevel analysis, the double and opposite effect of poverty on activity space according to individual or neighbourhood income indicates that the contextual effect of a neighbourhood's socioeconomic profile cannot be seen as a confounding factor of an individual's socioeconomic status. This double and opposite effect of poverty might also illustrate the danger of ecological fallacy, since it would be erroneous to infer, at the individual level, an association observed at the neighbourhood level. This ecological fallacy, which has been well known since the 1950s (Robinson, 1950), was underscored more recently in contextual analysis, social epidemiology and public health (Macintyre and Ellaway, 2000).

$\underline{\text { Investigating associations between our measure of activity space and participation in cervical }}$ screening

Health studies previously identified the link between functional limitation in daily activities and health services consumption in the elderly (Avlund et al., 2001; Chaix et al., 2005b; Fernandez-Mayoralas et al., 2000). With no age restrictions, a number of North American studies have also shown that women with reduced mobility are significantly less likely to avail themselves of cervical and breast cancer screening on a regular basis (Chevarley et al., 2006; Cooper and Yoshida, 2007; lezzoni et al., 2000; Nosek, 1998). In this research, a similar association in the Paris metropolitan area was observed, too, as women with a severe functional limitation had a greater likelihood of delayed cervical screening (Table 3). However, reducing daily mobility to its functional limitation dimension seems too restrictive. Indeed, in our study, positive and significant associations regarding delayed cervical screening were observed both with severe functional limitations and with an activity space limited to the perceived neighbourhood independently of other individual or neighbourhood characteristics. The effect of daily mobility on participation in preventive health-care activities can thus be fruitfully linked to both functional limitations and the activity space. It could thus 
be highly useful to take the activity space within or outside the perceived neighbourhood into consideration more often when studying health care utilization.

An activity space larger than the perceived neighbourhood might be seen as reflecting people's ability to move about and as resulting in a higher diversity of social interaction opportunities, which may contribute to modifying health-care norms. Through their daily activities, women may indeed become familiar with people, institutions, services, spatial structures, and norms - particularly health norms (Hanson, 2005) and, ultimately, may be more motivated to participate in cervical screening. This hypothesis is consistent with studies suggesting that one's social network may be important in determining health behaviour (Berkman et al., 2000). Two more-specific studies have also stressed the importance of social networks in cancer screening participation (Gotay and Wilson, 1998; Suarez et al., 2000).

Certain individual characteristics, such as origin and functional limitation status, were associated in the same direction with an activity space limited to the perceived neighbourhood (Table 2) and with delayed cervical screening (Table 3). Foreigners and those with a severe functional limitation had a statistically greater likelihood (i) of concentrating their daily activities within their perceived neighbourhood and (ii) of delayed cervical screening. We can thus suspect strong correlations between the measure of activity space, origin and functional limitation in the logistic regression concerning delayed cervical screening. Besides, we observed that certain characteristics, such as the mean neighbourhood income and location in the Paris metropolitan area, were associated in an opposite direction with an activity space limited to the perceived neighbourhood (Table 2) and with delayed cervical screening (Table 3). People living in wealthy neighbourhoods and in Paris did, in fact, have a greater likelihood (i) of concentrating their daily activities within their perceived neighbourhood, but a lower likelihood (ii) of delayed cervical screening. The measure of activity space is a useful variable that could not be summarized (or replaced) in the statistical models with other characteristics.

\section{Methodological comments}

Two methodological comments need to be made here. First, the data collected in 2005 were examined cross-sectionally. Therefore, we can only speculate on causal inferences. To understand the mechanism through which neighbourhood characteristics and activity space are associated with participation in preventive health-care activities, a longitudinal analysis will be performed as soon as data collected in 2009-10 on the same population (within the framework of the SIRS cohort) are available. Second, we determined the proportion of the neighbourhood population with a recent preventive consultation by aggregating information from the people surveyed in each census block. This aggregation procedure has often been 
used in multilevel analysis, for example, to create a neighbourhood deprivation index (Brown and Leyland, 2009; van Lenthe and Mackenbach, 2002). However, this procedure may have resulted in incorrect estimates of the health behaviour of the neighbourhood population.

\section{Relevance of neighbourhood characteristics in cervical screening participation}

Health care utilization has often been linked to the distance between a patient's residence and his/her provider's office. Recent advances in the field of health geography have identified associations between the spatial distribution of primary care services and health status (Gulliford, 2002) or health care utilization (Chaix et al., 2005b; Coughlin et al., 2008; Fortney et al., 1999; Nattinger et al., 2001). However, most of these studies were carried out either in rural areas or at the national level. In urban areas, some authors have pointed out that provider-to-population ratios in neighbourhoods have significant limitations, as these measures do not account for patient border crossing, which commonly occurs in small geographic areas, such as urban census blocks (Guagliardo, 2004). Some authors have therefore suggested considering the distribution of health-care opportunities within a spatial unit larger than the neighbourhood (such as a county), which would be more in line with the exposures supply-related characteristics of the health-care system (Litaker and Love, 2005). In our paper, the nonrelevance of neighbourhood practitioner density to delayed cervical screening in the general adult female population may have to do with the residents' overall mobility and the high practitioner density in the Paris metropolitan area. In the Paris area at least, but perhaps also, more generally, in urban areas with a high practitioner density, inequalities in participation in preventive health care may not be directly associated with the spatial distribution of primary care providers, with the notable exception of people whose activity space is limited. We did in fact observe that the provider-to-population ratio in a neighbourhood was statistically associated with participation in cervical screening among people with an activity space limited to their perceived neighbourhood of residence. In our opinion, it is not relevant to postulate that every urban resident has the ability to seek health care outside his/her neighbourhood of residence and to consequently assert that the neighbourhood is the wrong scale in urban areas for measuring the distribution of health-care opportunities.

We also observed that the odds ratios associated with the proportion of people with a recent preventive consultation were statistically greater for women whose daily activities were concentrated within their perceived neighbourhood. This greater sensitivity could be due to the fact that a limited activity space can prevent people from diversifying their social interaction opportunities. Spatial neighbourhood confinement may reduce the likelihood of being influenced by other women's health behaviours. Women who remain isolated in their neighbourhoods may thus be more inclined to adhere to the local community standard of 
health behaviour (Inagami et al., 2007). On the contrary, an activity space larger than the neighbourhood may permit exposure to other behavioural norms, thus creating an opportunity for adopting other habits. Urban geographers and environmental psychologists who have studied the role of daily mobility in neighbourhood attachment previously described daily travels within the overall city as a way to escape the constraints of the residential neighbourhood (Authier, 1999; Gustafson, 2009; Ramadier, 2007).

This paper might be useful for discussions of those aspects of a neighbourhood that might promote or hinder health services utilization. In research conducted in western Scotland starting in 1987, Macintyre and Ellaway conceptualized five "opportunity structures" of neighbourhoods that can influence health through the possibilities they provide to people (Macintyre and Ellaway, 2000; Macintyre and Ellaway, 2003). Apart from the physical features of the environment shared by all the residents in a given locality (such as air and water quality), the existence of healthy home, work and recreational environments and the area's reputation, these two researchers included sociocultural features (including norms and values) and the services provided in the neighbourhood to support people in their daily lives, such as education, transportation and health services. Our research found (i) that neighbourhood sociocultural features were associated with preventive health care in the general population and (ii) that the neighbourhood health services density and the health behaviours of the neighbourhood population were also associated with preventive health care, but only among people with an activity space limited to their perceived neighbourhood, who make up a sizeable proportion (20\%) of the Paris metropolitan area population, according to our definition. When examining the "opportunity structures" of neighbourhoods that could influence health, it might thus be relevant not only to consider the general population. but also to focus the analysis on the less mobile population.

\section{Conclusion}

Through the example concerning women's cervical screening behaviour in the Paris metropolitan area, this research provides strong arguments in favour of the influence of the activity space on participation in health-care activities. Studying people's activity helped elucidate how residential and nonresidential spaces matter in health behaviours. In the introduction of this paper, we mention studies that showed that the effect of the residential environment varies according to the resident's gender, age, race/ethnicity and socioeconomic status. With the notable exception of Inagami, Cohen and Finch's study of self-rated health (2007), these studies only allude to the role of daily mobility. Stafford, Cummins, Macintyre et al. write, for instance, that the "stronger association between neighbourhood characteristics and health seen amongst women may be due to the fact that 
women spend more of their time in the neighbourhood" (2005). Our paper shows that it may be useful to examine how activity space - measured in terms of the concentration of daily activities in the perceived neighbourhood - can modify the extent of residential neighbourhood effects on health-care behaviours. We believe that research on interactions between individual and neighbourhood characteristics on heath could be profitably developed, with special attention given to people's activity space.

This research might also contribute to the social sciences discussion of the importance to be attributed to the urban neighbourhood as a social space. In the Paris metropolitan area, we found that the neighbourhood of residence plays a significant role in the health behaviour of people whose daily activities are spatially limited, as it provides them with health-care facilities and social interaction opportunities.

\section{Funding/Support.}

The SIRS survey was supported by the French National Institute for Health and Medical Research (INSERM), the Institute for Public Health Research (IReSP), the DirectorateGeneral of Health (DGS), the Interministerial Delegation for Urban Affairs (DIV), the European Social Fund, the Regional Council of lle-de-France, and the City of Paris. Support for Julie Vallée's postdoctoral research was provided by the Fondation de France.

\section{Acknowledgements.}

We thank the reviewers for their valuable comments and suggestions regarding our manuscript. We also thank Anne-Lise Humain-Lamoure (Univ. Paris I - UMR GeographieCités) for her advice concerning the perceived neighbourhoods of the people living in the Paris metropolitan area and Nora Liberalotto (EHESS - CERMES) for her information on the organization of cervical screening in France.

\section{Ethics approval.}

This cohort study was approved by France's privacy and personal data protection authority (Commission Nationale de l'Informatique et des Libertés [CNIL]).

\section{No financial disclosure; no conflict of interest.}

\section{References}

ANDEM, 1995. Pratique des frottis cervicaux pour le dépistage et diagnostique biologique du cancer du col de l'utérus. Recommandations et Références Médicale. 
Andersen, R.M., 1995. Revisiting the Behavioral Model and Access to Medical Care: Does It Matter? Journal of Health and Social Behavior 36, 1-10.

Arcury, T.A., Gesler, W.M., Preisser, J.S., Sherman, J.E., Spencer, J., Perin, J., 2005. The Effects of Geography and Spatial Behavior on Health Care Utilization among the Residents of a Rural Region. Health Services Research 40:1, 135-155.

Authier, J.-Y., 1999. Le quartier à l'épreuve des mobilités "métapolitaines". Espaces, populations et sociétés 2, 291-306.

Avlund, K., Holm-Pedersen, P., Schroll, M., 2001. Functional ability and oral health among older people: a longitudinal study from age 75 to 80 . Journal of the American Geriatrics Society 49, 954-962.

Baker, D., Middleton, E., 2003. Cervical screening and health inequality in England in the 1990s. Journal of Epidemiology and Community Health 57, 417-423.

Benjamins, M.R., Kirby, J.B., Bond Huie, S.A., 2004. County characteristics and racial and ethnic disparities in the use of preventive services. Preventive Medicine 39, 704-712.

Berkman, L.F., Glass, T., Brissette, I., Seeman, T.E., 2000. From social integration to health: Durkheim in the new millennium. Social Science \& Medicine 51, 843-857.

Bourdieu, P., 2000. The weight of the world: social suffering in contemporary society. Stanford University Press.

Bowman, J.A., Redman, S., Dickinson, J.A., Gibberd, R., Sanson-Fisher, R.W., 1991. The Accuracy of Pap Smear Utilization Self-Report: A Methodological Consideration in Cervical Screening Research. Health Services Research 26:1, 97-107.

Brown, D., Leyland, A.H., 2009. Population mobility, deprivation and self-reported limiting longterm illness in small areas across Scotland. Health and Place 15 (1), 37-44.

Chaix, B., Merlo, J., Evans, D., Leal, C., Havard, S., 2009. Neighbourhoods in ecoepidemiologic research: delimiting personal exposure areas. A response to Riva, Gauvin, Apparicio and Brodeur. Soc Sci Med 69, 1306-1310.

Chaix, B., Merlo, J., Subramanian, S.V., Lynch, J., Chauvin, P., 2005a. Comparison of a spatial perspective with the multilevel analytical approach in neighborhood studies: the case of mental and behavioral disorders due to psychoactive substance use in Malmo, Sweden, 2001. Am J Epidemiol 162, 171-182.

Chaix, B., Rosvall, M., Merlo, J., 2007. Assessment of the magnitude of geographical variations and socioeconomic contextual effects on ischaemic heart disease mortality: a multilevel survival analysis of a large Swedish cohort. Journal of Epidemiology and Community Health 61, 349-355.

Chaix, B., Veugelers, P.J., Boelle, P.Y., Chauvin, P., 2005b. Access to general practitioner services: the disabled elderly lag behind in underserved areas. European Journal of Public Health 15, 282-287.

Chauvin, P., Parizot, I., 2009. Les inégalités sociales et territoriales de santé dans l'agglomération parisienne : une analyse de la cohorte SIRS, Editions de la DIV (coll. Les documents de l'ONZUS). http://i.ville.gouv.fr/Data/inserhitlien.php?id=5161, Paris.

Chevarley, F.M., Thierry, J.M., Gill, C.J., Ryerson, A.B., Nosek, M.A., 2006. Health, preventive health care, and health care access among women with disabilities in the 19941995 National Health Interview Survey, Supplement on Disability. Women's Health Issues 16, 297-312.

Cooper, N.S., Yoshida, K.K., 2007. Cancer screening behaviors among Canadian women living with physical disabilities. Archives of Physical Medicine and Rehabilitation 88, 597-603. 
Coughlin, S.S., Leadbetter, S., Richards, T., Sabatino, S.A., 2008. Contextual analysis of breast and cervical cancer screening and factors associated with health care access among United States women, 2002. Social Science \& Medicine 66, 260-275.

Coulton, C.J., Korbin, J., Chan, T., Su, M., 2001. Mapping residents' perceptions of neighborhood boundaries: a methodological note. Am J Community Psychol 29, 371-383.

Cromley, E.K., Shannon, G.W., 1986. Locating ambulatory medical care facilities for the elderly. Health Services Research 21(4), 499-514.

Cummins, S., 2007. Commentary: investigating neighbourhood effects on health-avoiding the 'local trap'. Int J Epidemiol 36, 355-357.

Cummins, S., Stafford, M., S, M., Marmot, M., Ellaway, A., 2005. Neighbourhood environment and its association with self rated health: evidence from Scotland and England. Journal of Epidemiology and Community Health 59, 207-213.

Diez- Roux, A., 2001. Investigating Neighborhood and Area Effects on Health. American Journal of Public Health 91(11), 1783-1789.

Ecob, R., Macintyre, S., 2000. Small area variations in health related behaviours; do these depend on the behaviour itself, its measurement, or on personal characteristics? Health and Place 6, 261-274.

Enaux, C., 2009. Processus de décision et Espace d'activités/déplacements. Une approche articulant routine cognitive et adaptation événementielle [Decision process and Activity space. An approach linking cognitive routine and occurrence adaptation]. European Journal of Geography - CyberGeo 453.

Fernandez-Mayoralas, G., Rodriguez, V., Rojo, F., 2000. Health services accessibility among Spanish elderly. Social Science \& Medicine 50, 17-26.

Fortney, J., Rost, K., Zhang, M., Warren, J., 1999. The impact of geographic accessibility on the intensity and quality of depression treatment. Medical Care 37, 884-893.

Gesler, W.M., Meade, M.S., 1988. Locational and population factors in health care-seeking behavior in Savannah, Georgia. Health Service Research 23, 443-462.

Golledge, R.G., Stimson, R.J., 1997. Spatial Behaviour - A geographic perspective. Guilford Press, New York.

Gotay, C.C., Wilson, M.E., 1998. Social support and cancer screening in African American, Hispanic, and Native American women. Cancer Practice 6, 31-37.

Guagliardo, M.F., 2004. Spatial accessibility of primary care: concepts, methods and challenges. International Journal of Health Geographics 3.

Guest, A.M., Lee, B.A., 1984. How urbanites define their neighborhoods. Population \& Environment 7, 32-56.

Gulliford, M.C., 2002. Availability of primary care doctors and population health in England: is there an association? J Public Health Med 24, 252-254.

Gustafson, P., 2009. Mobility and Territorial Belonging. Environment and Behavior 41(4), 490-508.

Hägerstrand, T., 1967. Innovation diffusion as a spatial process. University of Chicago Press, Chicago.

Hägerstrand, T., 1970. What about people in regional science? Papers of Regional Science Association 24, 7-21.

Haney, W., Knowles, E., 1978. Perception of neighborhoods by city and suburban residents. Human Ecology 6, 201-214. 
Hanson, S., 2005. Perspectives on the geographic stability and mobility of people in cities. Proceedings of the National Academy of Sciences of the United States of America 102, 15301-15306.

Humain-Lamoure, A.L., 2008. Faire des territoires de démocratie locale. Géographie sociopolitique des quartiers en Ile-de-France, sous la direction de T. Saint-Julien \& C. Grasland. [Doctoral thesis in geography]. Université Paris 1.

lezzoni, L.I., McCarthy, E.P., Davis, R.B., Siebens, H., 2000. Mobility impairments and use of screening and preventive services. American Journal of Public Health 90, 955-961.

Inagami, S., Cohen, D.A., Finch, B.K., 2007. Non-residential neighborhood exposures suppress neighborhood effects on self-rated health. Social Science \& Medicine 65, 17791791.

INCa, 2007. Etat des lieux du dépistage du cancer du col utérin en France. Rapports \& synthèse.

Jakle, J.A., Brunn, S., Roseman, C.C., 1976. Human spatial behavior: A social geography. Duxbury Press.

Kaufmann, V., 2002. Re-thinking mobility. Contemporary sociology. Ashgate, Aldershot.

Kwan, M.-P., 1999. Gender and Individual Access to Urban Opportunities:A Study Using Space-Time Measures. Professional Geographer 51(2), 210-227.

Kwan, M.-P., Lee, J., 2003. Geovisualization of Human Activity Patterns Using 3D GIS: A Time-Geographic Approach In: Goodchild, M., Janelle, D. (Eds.), Spatially Integrated Social Science: Examples in Best Practice. Oxford University Press.

Lee, B.A., Campbell, K.E., 1997. Common ground ? Urban neighborhoods as survey respondents see them. Social science quarterly 78, 922-936

Lefever, D.W., 1926. Measuring geographic concentration by means of the standard deviational ellipse. American Journal of Sociology 32, 88-94.

Litaker, D., Love, T.E., 2005. Health care resource allocation and individuals' health care needs: examining the degree of fit. Health Policy 73, 183-193.

Logan, J.R., Collver, A., 1983. Residents' Perceptions of Suburban Community Differences. American Sociological Review 48, 428-433.

Löytönen, M., 1998. GIS, Time Geography and Health. In: Gatrell, A.C., Loytonen, M. (Eds.), GIS and Health. Taylor and Francis, London, pp. 97-110.

Macintyre, S., 2001. Inequalities in health: is research gender blind? In: Leon, D., Walt, G. (Eds.), Poverty, inequality and health, Oxford: Oxford University Press.

Macintyre, S., Ellaway, A., 2000. Ecological approaches: Rediscovering the role of the physical and social environment. In: Berkman, L.F., Kawachi, I. (Eds.), Social Epidemiology, New York: Oxford University Press, pp. 332-348.

Macintyre, S., Ellaway, A., 2003. Neighborhoods and Health: an overview. In: Kawachi, I., Berkman, L.F. (Eds.), Neighborhoods and Health, Oxford Press, pp. 20-42.

Nattinger, A.B., Kneusel, R.T., Hoffmann, R.G., Gilligan, M.A., 2001. Relationship of distance from a radiotherapy facility and initial breast cancer treatment. Journal of the National Cancer Institute 93, 1344-1346.

Nemet, G.F., Bailey, A.J., 2000. Distance and health care utilization among the rural elderly. Social Science \& Medicine 50, 1197-1208.

Nosek, M.A., 1998. Use of cervical and breast cancer screening among women with and without functional limitations--United States, 1994-1995. MMWR Morbidity and mortality weekly report $47,853-856$. 
Préteceille, E., 2003. La division sociale de l'espace francilien. Typologie socioprofessionnelle 1999 et transformations de l'espace résidentiel 1990-99. Observatoire sociologique du changement.

Raleigh, V.S., Kiri, V.A., 1997. Life expectancy in England: variations and trends by gender, health authority, and level of deprivation. Journal of Epidemiology and Community Health 51(6), 649-658.

Ramadier, T., 2007. Mobilité quotidienne et attachement au quartier : une question de position? In: Authier, J.-Y., Bacqué, M.-H., Guerin-Pace, F. (Eds.), Le quartier : Enjeux scientifiques, actions politiques et pratiques sociales. La Découverte, Paris, pp. 127-138.

Renahy, E., Parizot, I., Chauvin, P., 2008. Health information seeking on the Internet: a double divide? Results from a representative survey in the Paris metropolitan area, France, 2005-2006. BMC Public Health 8:69.

Robinson, W., 1950. Ecological correlations and the behavior of individuals. American Sociological Review 15, 351-357.

Sastry, N., Pebley, A.R., Zonta, M., 2002. Neighborhood Definitions and the Spatial Dimension of Daily Life in Los Angeles. UC Los Angeles: California Center for Population Research.

Schaerstrom, A., 1996. Pathogenic Paths? a Time Geographical Approach to Medical Geography. Lund University Geographical Studies. No 125.

Schootman, M., Jeffe, D.B., Baker, E.A., Walker, M.S., 2006. Effect of area poverty rate on cancer screening across US communities. Journal of Epidemiology and Community Health 60, 202-207.

Shannon, G.W., Bashshur, R.L., Spurlock, C.W., 1978. The search for medical care: an exploration of urban black behavior. International journal of health services 8(3), 519-530.

Sherman, J.E., Spencer, J., Preisser, J.S., Gesler, W.M., Arcury, T.A., 2005. A suite of methods for representing activity space in a healthcare accessibility study. International Journal of Health Geographics 4.

Stafford, M., Bartley, M., Mitchell, R., Marmot, M., 2001. Characteristics of individuals and characteristics of areas: investigating their influence on health in the Whitehall II study. Health and Place 7, 117-129.

Stafford, M., Cummins, S., Macintyre, S., Ellaway, A., Marmot, M., 2005. Gender differences in the associations between health and neighbourhood environment. Social Science \& Medicine 60, 1681-1692.

Suarez, L., Ramirez, A.G., Villarreal, R., Marti, J., McAlister, A., Talavera, G.A., Trapido, E., Perez-Stable, E.J., 2000. Social networks and cancer screening in four U.S. Hispanic groups. American Journal of Preventive Medicine 19, 47-52.

Vallée, J., 2009. Les disparités spatiales de santé en ville. L'exemple de Vientiane (Laos) [Spatial health disparities within city: the case of Vientiane, Lao PDR]. European Journal of Geography - Cybergeo article 477.

Vallée, J., Souris, M., Fournet, F., Bochaton, A., Mobillion, V., Peyronnie, K., Salem, G., 2007. Sampling in health geography: reconciling geographical objectives and probabilistic methods. An example of a health survey in Vientiane (Lao PDR). Emerging Themes in Epidemiology 4(6).

van Lenthe, F.J., Mackenbach, J.P., 2002. Neighbourhood deprivation and overweight: the GLOBE study. International Journal of Obesity 26, 234-240.

Waitzman, N.J., Smith, K.R., 1998. Phantom of the area: poverty-area residence and mortality in the United States. American Journal of Public Health 88(6), 973-976. 
Watts, S., Khallaayoune, K., Bensefia, R., Laamrani, H., Gryseels, B., 1998. The study of human behavior and schistosomiasis transmission in an irrigated area in Morocco. Social Science \& Medicine 46(6), 755-765.

Yen, I., Kaplan, G., 1999. Neighborhood social environment and risk of death: multilevel evidence from the Alameda County Study. American Journal of Epidemiology 149, 898-907.

Yuill, R.S., 1971. The standard deviational ellipse: an updated tool for spatial description. Geografiska Annaler 53B, 28-39. 